WAMSER AF; BECKER WF; SANTOS JP; MUELLER S. 2008. Influência do sistema de condução do tomateiro sobre a incidência de doenças e insetos-praga. Horticultura Brasileira 26: 180-185.

\title{
Influência do sistema de condução do tomateiro sobre a incidência de doenças e insetos-praga
}

\author{
Anderson Fernando Wamser; Walter F Becker; Janaína P dos Santos; Siegfried Mueller \\ EPAGRI-EE de Caçador, C. Postal 591, 89500-000 Caçador-SC; afwamser@epagri.sc.gov.br
}

\section{RESUMO}

Avaliou-se o efeito dos métodos de tutoramento e de condução de plantas de tomate sobre a severidade de doenças foliares e sobre a incidência de pragas em frutos em diferentes cultivares. Dois experimentos foram realizados em 2004/2005 e 2005/2006 em Caçador, SC. Os tratamentos consistiram da combinação de duas cultivares (Carmen e Débora Max, em 2004/2005, e Nemo Netta e San Vito, em 2005/2006); quatro métodos de tutoramento (cruzado, 'mexicano', vertical com bambu e vertical com fitilho) e dois métodos de condução de plantas (com uma e duas hastes por planta mantendo o mesmo número de hastes por área) em parcelas sub-subdivididas. Foram avaliadas as severidades de requeima, pinta-preta e mancha bacteriana nas folhas e a porcentagem de frutos com danos causados por doenças fisiológicas ou fitopatológicas e por brocas. Os métodos de tutoramento vertical proporcionaram menor severidade de requeima, pinta-preta e mancha bacteriana nas folhas e ataque de brocas nos frutos, em relação ao método de tutoramento cruzado. A severidade de doenças foliares e porcentagem de frutos com ataque de brocas não diferiram entre métodos de condução de plantas.

Palavras-chave: Lycopersicon esculentum, tutoramento, severidade de doenças, danos de insetos-praga.

\begin{abstract}
Influence of the training systems of tomato plants on the incidence of diseases and insect-pests

The effect of different methods of staking and training tomato plants was investigated to determine the severity of leaf damage and the incidence of pests in fruits of different cultivars. Two experiments were carried out in 2004/2005 and 2005/2006, in Caçador, Santa Catarina State, Brazil. The treatments consisted of the combination of two cultivars, Carmen and Débora Max, in 2004/2005, and Nemo Netta and San Vito, in 2005/2006; four staking methods, crossed fence, 'Mexican', vertical staking with bamboo and vertical staking with polypropylene cord; and two training methods, one and two stems per plant keeping the same number of stems per area. Severities of late blight, early blight and bacterial spot in leaves and the percentage of fruits with physiological and phytopathological diseases and with insect damages were evaluated. All vertical staking methods provided smaller severity of late blight, early blight and bacterial spot in leaves and attack of insects than crossed fence method. The severity of leaf diseases and percentage of fruits with insect damages did not differ among plant training methods.
\end{abstract}

Keywords: Lycopersicon esculentum, staking methods, diseases severity, insect-pest damages.

(Recebido para publicação em 18 dezembro de 2007; aceito em 11 de abril de 2008)

$\mathrm{O}$ sistema de produção de tomate na região do Alto Vale do Rio do Peixe, Meio-Oeste Catarinense, se baseia no monocultivo, na excessiva mobilização do solo e na utilização indiscriminada de água e insumos agrícolas (Tagliari, 2003). $\mathrm{O}$ uso intensivo de insumos, principalmente defensivos para o controle de insetos-praga e fitopatógenos, é considerado um dos principais problemas da atividade na região (Kreuz, 2003), podendo proporcionar aumento do custo de produção, contaminação do ambiente, intoxicação de indivíduos envolvidos com a cultura e contaminação do produto colhido (Tagliari, 2003; Melo \& Vilela, 2005). O número elevado de pulverizações, chegando a três aplicações semanais de defensivos, decorre das condições propícias às principais doenças do tomateiro, como temperatura noturna amena e precipitações constantes entre os meses de dezembro e fevereiro, além do ataque de insetos-praga.
Dentre as principais doenças que incidem no tomateiro na região do Alto Vale do Rio do Peixe se destacam a requeima (Phytophthora infestans), a pinta-preta (Alternaria solani) e a mancha bacteriana (Xanthomonas campestris pv. vesicatoria) (Epagri, 1997). Entre os insetos-praga se destacam a broca-pequena-do-tomateiro [Neoleucinoides elegantalis (Guenée)] (Lepidoptera: Crambidae) e a broca-grande [Helicoverpa zea (Boddie)] (Lepidoptera: Noctuidae), que causam danos diretos nos frutos, depreciando a aparência e os tornando inviáveis para a comercialização (Epagri, 1997).

A redução do uso de defensivos com significativo controle de pragas, sem a perda da qualidade do produto colhido, exige a adoção de práticas de manejo integrado que permitam seu controle eficiente (Becker, 2005). Várias práticas de manejo podem influenciar a sanidade das plantas, dentre essas os mé- todos de tutoramento e condução de plantas, que têm papel importante na incidência de insetos-praga e doenças (Boff et al., 1991; Picanço et al., 1995).

O principal sistema de condução de plantas empregado na região do Alto Vale do Rio do Peixe é o tutoramento cruzado, também denominado de "V" invertido, com a condução de duas hastes por planta. Esse método forma um ambiente úmido e aquecido sob o "V" invertido, favorável ao desenvolvimento de fitopatógenos (Rebelo, 1993). Além disso, a aplicação de defensivos nos órgãos das plantas localizados em seu interior é deficiente, dificultando o controle de insetos-praga (Picanço et al., 1995) e doenças (Boff et al., 1992).

O tutoramento vertical de plantas, por sua vez, aumenta a radiação solar e a ventilação ao longo do dossel das plantas podendo reduzir, desta forma, o período de molhamento foliar e a severidade de doenças (Santos et al., 1999). 
Além disso, a aplicação de defensivos é mais eficiente nos dois lados das plantas ao longo das filas (Picanço et al., 1995), possibilitando maior cobertura dos produtos nos órgãos das plantas e favorecendo o controle de pragas. Devido a essas características, o tutoramento vertical de plantas vem sendo adotado por muitos produtores da região. Porém, existem diferentes métodos empregados, destacando-se o tutoramento vertical com varas de bambus ou com fitilho e o 'mexicano' (Wamser et al., 2007). Neste último, as plantas não são amarradas a tutores, sendo conduzidas verticalmente entre fitilhos que são dispostos horizontalmente nos dois lados das plantas à medida que as hastes crescem. Paralelamente ao método de condução, preconiza-se a redução do espaçamento entre plantas e a condução de uma haste por planta com o objetivo de aumentar a produção de frutos (Wamser et al., 2007).

A severidade de doenças e o ataque de insetos-praga podem variar em função dos métodos de condução e de tutoramento de plantas, bem como em relação às diferentes cultivares empregadas em cada região. $\mathrm{O}$ objetivo do presente trabalho foi avaliar o efeito dos métodos de tutoramento (cruzado, vertical com bambu, vertical com fitilho e 'mexicano') e dos métodos de condução de plantas (com uma e duas hastes por planta) sobre a severidade de doenças foliares e sobre os danos em frutos causados por doenças e insetos, em quatro cultivares de tomateiro.

\section{MATERIAL E MÉTODOS}

Dois experimentos foram realizados nas safras de 2004/2005 e 2005/2006 na Epagri-EE de Caçador, no município de Caçador (SC), região fisiográfica do Alto Vale do Rio do Peixe. O clima da região é temperado constante úmido, com verão ameno, do tipo $\mathrm{Cfb}$, conforme a classificação de Köepen (Pandolfo et al., 2002). Os solos nos locais dos experimentos foram identificados como Latossolo Bruno distrófico típico (Embrapa, 1999) com as características: $\mathrm{pH}$ (água) $=5,8$ e 5,9, $\mathrm{P}=12,8$ e 19,2 $\mathrm{mg} / \mathrm{L}, \mathrm{K}=166$ e $72 \mathrm{mg} / \mathrm{L}, \mathrm{MO}=3,5$ e
$4,9 \%, \mathrm{Al}=0,0$ e $0,0 \mathrm{cmol}_{\mathrm{c}} / \mathrm{L}, \mathrm{Ca}=6,8$ e $8,5 \mathrm{cmol}_{\mathrm{c}} / \mathrm{L}, \mathrm{Mg}=3,6$ e $4,7 \mathrm{cmol} / \mathrm{L}, \mathrm{V}=$ 69 e $75 \%$ para os anos agrícolas de 2004/ 2005 e 2005/2006, respectivamente.

Os tratamentos consistiram na combinação de duas cultivares de tomate (Carmen e Débora Max, na safra 2004/ 2005, e San Vito e Nemo Netta, na safra 2005/2006), quatro métodos de tutoramento e dois métodos de condução. As cultivares Carmen e Nemo Netta pertencem ao grupo Salada e as cultivares Débora Max e San Vito são dos grupos Santa Cruz e Saladete, respectivamente, todas de crescimento indeterminado. Os métodos de tutoramento testados foram cruzado, 'mexicano', vertical com bambu e vertical com fitilho. Os métodos de condução foram uma haste por planta e duas hastes por planta. $\mathrm{O}$ delineamento experimental foi de parcelas sub-subdivididas, com quatro repetições, alocandose o fator cultivar na parcela, o fator método de tutoramento na subparcela e o fator método de condução na subsubparcela.

$\mathrm{O}$ espaçamento entre plantas nas cultivares Carmen, Débora Max e Nemo Netta foi de 0,3 e $0,6 \mathrm{~m}$ para as plantas conduzidas com uma e duas hastes, respectivamente. Para a cultivar San Vito utilizou-se espaçamento entre plantas de 0,2 e $0,4 \mathrm{~m}$ para a condução de uma e duas hastes por planta, respectivamente. Desta forma, dentro do fator método de condução, as parcelas tinham o mesmo número de hastes por área em cada cultivar. As parcelas dos métodos de tutoramento vertical foram constituídas de uma linha de plantas com $9 \mathrm{~m}$ de comprimento. Já no método de tutoramento cruzado as parcelas possuíam duas linhas de plantas, com espaçamento de $1,0 \mathrm{~m}$ entre as linhas que formam o "V" invertido. O espaçamento entre linhas para todos os métodos de tutoramento foi de $1,5 \mathrm{~m}$.

Utilizou-se o sistema de plantio direto sobre a cultura da aveia preta, sem aplicação de herbicida. A adubação de base foi feita no sulco, utilizando $60 \mathrm{~kg} /$ ha de $\mathrm{N}, 600 \mathrm{~kg} / \mathrm{ha}$ de $\mathrm{P}_{2} \mathrm{O}_{5}$ e $300 \mathrm{~kg} / \mathrm{ha}$ de $\mathrm{K}_{2} \mathrm{O}$ da fórmula 03-30-15, 10 tha de esterco de aves, $2,7 \mathrm{~kg} / \mathrm{ha}$ de B como bórax e $8 \mathrm{~kg} / \mathrm{ha}$ de $\mathrm{Zn}$ como sulfato de zinco nas cultivares Carmen, Débora
Max e Nemo Netta, e $90 \mathrm{~kg} / \mathrm{ha}$ de N, $900 \mathrm{~kg} / \mathrm{ha}$ de $\mathrm{P}_{2} \mathrm{O}_{5}$ e $450 \mathrm{~kg} / \mathrm{ha}$ de $\mathrm{K}_{2} \mathrm{O}$ da fórmula $03-30-15,15$ t/ha de esterco de aves, 4,1 kg/ha de B como bórax e $60 \mathrm{~kg} / \mathrm{ha}$ de $\mathrm{Zn}$ como sulfato de zinco na cultivar San Vito. A adubação diferenciada entre a cultivar San Vito e as demais foi realizada de forma a fornecer a mesma quantidade de adubação por haste para todas as cultivares.

As mudas de tomate foram produzidas no sistema "float" com a semeadura realizada em 03/11/04 e 14/10/05. O plantio foi realizado em 30/11/04 e 07/ $11 / 05$. O replantio de mudas foi realizado na primeira semana de plantio. Foram realizadas desbrotas semanais e, aos 120 dias após o plantio (DAP), a desponta em todos os tratamentos a partir da terceira folha acima do último cacho de cada haste. As adubações de cobertura foram realizadas semanalmente a partir dos $20 \mathrm{DAP}$, totalizando $450 \mathrm{~kg} /$ ha de $\mathrm{N}$ e de $\mathrm{K}_{2} \mathrm{O}$ nas cultivares Carmen, Débora Max e Nemo Netta, e 675 $\mathrm{kg} / \mathrm{ha}$ de $\mathrm{N}$ e de $\mathrm{K}_{2} \mathrm{O}$ na cultivar San Vito.

Os ingredientes ativos utilizados para o controle de insetos-praga e doenças, bem como a época e o número de aplicações, foram: acefato, $2 \mathrm{x}$ (nov), $5 \mathrm{x}$ (dez) e 1x (jan) em 2004/2005, e 1x (nov) e 3x (dez) em 2005/2006; Bacillus thuringiensis, $1 \mathrm{x}$ (jan) e $3 \mathrm{x}$ (fev) em 2005/2006; deltametrina, 1x (jan), 2x (fev) e 1x (mar) em 2004/2005, e 1x (fev) e 1x (mar) em 2005/2006; diflubenzurom, 1x (jan) em 2004/2005, e 1x (fev) em 2005/2006; fenitrotiona, 1x (nov), 2x (jan) e 1x (fev) em 2004/ 2005, e 1x (mar) em 2005/2006; imidacloprid, 1x (nov) em 2004/2005, e 1x (nov), 1x (dez) e 2x (fev) em 2005/ 2006; metomil, 2x (jan) e 1x (fev) em 2005/2006; tiametoxam, 2x (dez) e 1x (jan) em 2004/2005, e 2x (dez) e 1x (jan) em 2005/2006; tebufenozide, 1x (mar) em 2004/2005, e 2x (mar) em 2005/ 2006; abamectina, 1x (mar) em 2004/ 2005; óxido cuproso, 3x (dez), 6x (jan), 1x (fev) e 2x (mar) em 2004/2005, e 2x (dez) e 1x (jan) em 2005/2006; oxicloreto de cobre, 2x (mar) em 2005/ 2006; hidróxido de cobre, $3 \mathrm{x}$ (jan), 5x (fev) e 1x (mar) em 2005/2006; mancozeb, 2x (nov), 3x (dez) e 4x (jan) em 2004/2005, e 3x (dez), 1x (jan) e 3x 
Tabela 1. Severidade de requeima, pinta preta e mancha bacteriana em folhas de tomateiro em função da cultivar, método de tutoramento e método de condução de plantas. Caçador, EPAGRI, 2005.

\begin{tabular}{|c|c|c|c|c|c|}
\hline \multirow[b]{2}{*}{ Fatores } & \multicolumn{2}{|c|}{ Safra 2004/2005 } & \multicolumn{3}{|c|}{ Safra $2005 / 2006$} \\
\hline & $\begin{array}{c}\text { Pinta } \\
\text { preta }(\%)\end{array}$ & $\begin{array}{c}\text { Mancha } \\
\text { bacteriana (\%) }\end{array}$ & $\begin{array}{l}\text { Requeima } \\
(\%)\end{array}$ & $\begin{array}{c}\text { Pinta } \\
\text { preta }(\%)\end{array}$ & $\begin{array}{c}\text { Mancha } \\
\text { bacteriana (\%) }\end{array}$ \\
\hline \multicolumn{6}{|l|}{ Cultivar } \\
\hline Carmen & $0,14^{\text {ns } 1}$ & $1,19^{\text {ns }}$ & - & - & - \\
\hline Débora Max & 0,17 & 1,23 & - & - & - \\
\hline Nemo Netta & - & - & $0,19^{\text {int }}$ & $0,10^{\text {ns }}$ & $5,05^{\text {int }}$ \\
\hline San Vito & - & - & 2,09 & 0,16 & 2,87 \\
\hline \multicolumn{6}{|c|}{ Método de tutoramento } \\
\hline Cruzado & $0,21^{\text {ns }}$ & $1,42 \mathrm{a}$ & $4,40^{\text {int }}$ & $0,37 \mathrm{a}$ & $7,71 \mathrm{a}$ \\
\hline 'Mexicano' & 0,17 & $1,21 a b$ & 0,06 & $0,03 \mathrm{~b}$ & $3,89 \mathrm{~b}$ \\
\hline $\begin{array}{l}\text { Vertical com } \\
\text { bambu }\end{array}$ & 0,16 & $1,11 \mathrm{~b}$ & 0,04 & $0,05 \mathrm{~b}$ & $2,33 \mathrm{~b}$ \\
\hline Vertical com fitilho & 0,07 & $1,10 \mathrm{~b}$ & 0,07 & $0,07 \mathrm{~b}$ & $1,92 \mathrm{~b}$ \\
\hline \multicolumn{6}{|c|}{$\begin{array}{l}\text { Método de condução } \\
\text { (número de hastes por planta) }\end{array}$} \\
\hline Uma haste & $0,16^{\text {ns }}$ & $1,24^{\text {ns }}$ & $1,60^{\text {ns }}$ & $0,12^{\text {ns }}$ & $5,74^{\text {int }}$ \\
\hline Duas hastes & 0,15 & 1,18 & 0,68 & 0,14 & 2,19 \\
\hline Média & 0,16 & 1,21 & 1,14 & 0,13 & 3,96 \\
\hline CV (\%) & 17,7 & 6,9 & 46,7 & 14,5 & 31,7 \\
\hline
\end{tabular}

${ }^{1}$ Médias seguidas pela mesma letra na coluna, dentro de cada fator analisado, não diferem entre si pelo teste de Tukey $(\alpha=0,05)$; ${ }^{\text {ns }}$ não houve diferenças significativas entre tratamentos pelo teste $F(p>0,05)$; ${ }^{\text {int }}$ houve interação significativa entre fatores pelo teste $F(p \leq 0,05)$.

(fev) em 2005/2006; clorotalonil, 1x (nov), 3x (dez), 3x (jan) e 1x (fev) em 2004/2005, e 3x (nov) e 2x (dez) em 2005/2006; metiram + piraclostrobina, $3 x$ (fev) e 1x (mar) em 2004/2005, e 1x (dez) em 2005/2006; cimoxanil + mancozebe, 1x (jan) em 2004/2005, e 1x (fev) em 2005/2006; mancozebe + metalaxil-M, 1x (dez) e 1x (jan) em 2004/2005, e 1x (mar) em 2005/2006; captana, 1x (jan) e 1x (mar) em 2004/ 2005, e 1x (fev) e 3x (mar) em 2005/ 2006; iprodiona, $1 \mathrm{x}$ (jan) em 2004/2005, e $3 x$ (fev) e $1 x$ (mar) em 2005/2006; metiram, 1x (jan) em 2005/2006; clorotalonil + cloridrato de propamocarb, 2x (jan) em 2005/2006; clorotalonil + dimetomorfe, $2 \mathrm{x}$ (jan) em 2005/2006; cimoxanil + famoxadona, 1x (jan) em 2005/2006; famoxadona + mancozebe, 1x (fev) em 2005/2006. As doses aplicadas seguem as recomendadas para a cultura e praga. Demais práticas culturais foram realizadas de acordo com as Normas técnicas para o tomateiro tutorado na região do Alto Vale do Rio do Peixe (Epagri, 1997).

Os valores diários de precipitação, umidade relativa e temperaturas máxima e mínima durante o ciclo da cultura foram obtidos na estação meteorológica

\section{da Estação Experimental de Caçador.}

Nas duas safras foram avaliadas as severidades de requeima, pinta-preta e mancha bacteriana nas folhas de três plantas por parcela, a porcentagem dos frutos colhidos com danos causados por doenças fisiológicas ou fitopatológicas e a porcentagem dos frutos colhidos com danos causados por brocas em geral. A severidade de doenças foi avaliada aos 92 DAP e 128 DAP, nas safras 2004/ 2005 e 2005/2006, respectivamente, com auxílio de escalas diagramáticas para requeima (James, 1971), pinta-preta (Boff et al., 1991) e mancha bacteriana (Mello et al., 1997). Na safra 2005/ 2006 a porcentagem de danos nos frutos causados por brocas foram separados em danos da broca-pequena-do-tomateiro e da broca-grande. Esta separação foi feita de acordo com o tipo de dano nos frutos. A broca-grande faz danos superficiais, de formato irregular e de fora para dentro do fruto. A brocapequena-do-tomateiro penetra nos frutos, se alimenta da polpa e deixa pequenos orifícios ao sair, próximo à maturação do fruto (Epagri, 1997). As variáveis foram submetidas à análise de variância (teste $F$ ). Quando alcançada significância estatística $(\mathrm{p} \leq 0,05)$, as médias dos tratamentos foram comparadas pelo teste de Tukey ao nível de 5\% de significância.

\section{RESULTADOS E DISCUSSÃO}

A precipitação total e o número de dias de chuva durante o ciclo da cultura na safra 2004/2005 foi de 321,1 mm e 41 dias, respectivamente. Na média do ciclo da cultura, para esta safra, a umidade relativa (UR\%) ficou em 76,0\% enquanto que as temperaturas máxima e mínima ficaram em 26,9 e $15,6^{\circ} \mathrm{C}$, respectivamente. Já na safra 2005/2006, a precipitação total e o número de dias de chuva durante o ciclo da cultura foram maiores que na safra 2004/2005, ficando em 514,8 mm e 61 dias, respectivamente. A UR\% e as temperaturas máxima e mínima, médias do ciclo, também foram maiores na safra 2005/2006, ficando em $80,9 \%, 28,7$ e $16,8^{\circ} \mathrm{C}$, respectivamente.

Doenças foliares - A incidência de requeima foi observada somente na safra 2005/2006, enquanto que a pintapreta e a mancha bacteriana ocorreram nas duas safras (Tabela 1). Todas as cultivares utilizadas não apresentam resistência à requeima, mancha bacteriana e pinta-preta (Agrocinco, 2006; Sakata Seed Sudamerica, 2006). Desta forma, as maiores precipitações, dias de chuva e UR\% ocorridas na safra 2005/2006 podem ter favorecido o desenvolvimento do fitopatógeno e dificultado o controle da requeima nesta safra. Segundo Kurozawa \& Pavan (2005), a requeima necessita de alta umidade e temperatura em torno de $20^{\circ} \mathrm{C}$ para se desenvolver. Além disso, a orientação das fileiras de plantas foi no sentido leste-oeste em 2004/2005 e norte-sul em 2005/ 2006. A orientação leste-oeste possibilita a maior insolação no dossel das plantas ao longo do dia, diminuindo o período de molhamento foliar causado por chuvas e orvalho, fator que favorece o desenvolvimento desta doença (Becker, 2005).

Entre as cultivares, foram observadas diferenças significativas somente para requeima e mancha bacteriana na safra 2005/2006 (Tabelas 1 e 2). A severidade da requeima para cada cultivar variou de acordo com o método de 
tutoramento, existindo diferenças somente no método de tutoramento cruzado, com maior severidade na cultivar San Vito, em relação a Nemo Netta. Possivelmente na cultivar San Vito, a utilização de menor espaçamento entre plantas (0,4 e 0,2 m), associado ao método de tutoramento cruzado, permitiu a formação de microclima favorável ao desenvolvimento da doença, além da menor eficiência na aplicação dos defensivos. Já para a severidade de mancha bacteriana, houve diferenças entre as cultivares somente quando foi utilizada a condução de uma haste por planta, com maior severidade na cultivar San Vito (Tabela 2). A distribuição mais equiidistante entre hastes com a condução de uma haste por planta, em relação à condução de duas hastes, na cultivar San Vito, pode ter favorecido a disseminação da mancha bacteriana por meio dos respingos de chuva, principal forma de disseminação da doença planta a planta (Kurozawa \& Pavan, 2005).

Entre os métodos de tutoramento, foram observadas diferenças significativas para severidade de mancha bacteriana, na safra 2004/2005 e 2005/2006, para pinta-preta, na safra 2005/2006, e para requeima na cultivar San Vito, na safra 2005/2006 (Tabelas 1 e 2). Para todas estas doenças e safras, o método de tutoramento cruzado apresentou maior severidade em relação aos métodos de tutoramento vertical, não diferindo do método 'mexicano', na safra 2004/2005. Em trabalhos anteriores, não foram observadas diferenças entre métodos de tutoramento cruzado e vertical para a porcentagem de área foliar infectada por pinta-preta, septoriose (Septoria lycopersici) (Santos et al., 1999), mancha de estenfílio (Stemphylium solani) (Boff et al., 1991). Entretanto, maiores valores de incidência de pinta-preta foram observados no método vertical por Boff et al. (1991). Os resultados do presente trabalho confirmam o pressuposto de que o tutoramento vertical promove condições menos favoráveis às doenças (Picanço et al., 1995; Santos et al., 1999). Comparando somente os métodos de tutoramento vertical, não houve diferenças para todas as doenças analisadas, embora o método 'mexicano' não tenha se diferenciado do cruzado para man-

Tabela 2. Severidade de requeima, em função da cultivar e do método de tutoramento, e de mancha bacteriana, em função da cultivar e do método de condução, em folhas de tomateiro. Caçador, EPAGRI, 2005.

\begin{tabular}{|c|c|c|}
\hline \multirow{4}{*}{ Fatores } & \multicolumn{2}{|c|}{ Cultivar } \\
\hline & Nemo Netta & San Vito \\
\hline & \multicolumn{2}{|c|}{$\%$} \\
\hline & \multicolumn{2}{|c|}{ Requeima } \\
\hline \multicolumn{3}{|c|}{ Método de tutoramento } \\
\hline Cruzado & $0,66 \mathrm{aB}^{1}$ & 8,14 aA \\
\hline 'Mexicano' & 0,03 aA & $0,08 \mathrm{bA}$ \\
\hline Vertical com bambu & 0,04 aA & $0,04 \mathrm{bA}$ \\
\hline \multirow[t]{2}{*}{ Vertical com fitilho } & 0,04 aA & $0,11 \mathrm{bA}$ \\
\hline & \multicolumn{2}{|c|}{ Mancha bacteriana } \\
\hline \multicolumn{3}{|c|}{$\begin{array}{l}\text { Método de condução } \\
\text { (número de hastes por planta) }\end{array}$} \\
\hline Uma haste & $2,42 \mathrm{aB}$ & 7,69 aA \\
\hline Duas hastes & 1,96 aA & $3,78 \mathrm{bA}$ \\
\hline
\end{tabular}

${ }^{1}$ Médias seguidas pela mesma letra minúscula na coluna e maiúscula na linha, dentro de cada fator analisado, não diferem entre si pelo teste de Tukey $(\alpha=0,05)$.

Tabela 3. Porcentagem de frutos com doenças e atacados por brocas, em relação ao número total de frutos, em função da cultivar, do método de tutoramento e do método de condução de plantas de tomate. Caçador, EPAGRI, 2005.

\begin{tabular}{|c|c|c|c|c|c|c|}
\hline \multirow{3}{*}{ Fatores } & \multicolumn{2}{|c|}{ Safra 2004/2005 } & \multicolumn{4}{|c|}{ Safra $2005 / 2006$} \\
\hline & Doente & $\begin{array}{l}\text { Brocas } \\
\text { totais }\end{array}$ & Doente & $\begin{array}{c}\text { Brocas } \\
\text { totais }\end{array}$ & $\begin{array}{c}\text { Broca } \\
\text { grande }\end{array}$ & $\begin{array}{c}\text { Broca } \\
\text { pequena }\end{array}$ \\
\hline & \multicolumn{6}{|c|}{$\%$} \\
\hline
\end{tabular}

\begin{tabular}{|c|c|c|c|c|c|c|}
\hline \multicolumn{7}{|l|}{ Cultivar } \\
\hline Carmen & $1,9 a^{1}$ & $1,1^{\text {ns }}$ & - & - & - & - \\
\hline Débora Max & $1,4 \mathrm{~b}$ & 1,1 & - & - & - & - \\
\hline Nemo Netta & - & - & $0,6 \mathrm{~b}$ & $1,5 \mathrm{~b}$ & $0,7 \mathrm{~b}$ & $0,8 \mathrm{~b}$ \\
\hline San Vito & - & - & $7,1 \mathrm{a}$ & $2,1 \mathrm{a}$ & $1,0 \mathrm{a}$ & $1,1 \mathrm{a}$ \\
\hline \multicolumn{7}{|c|}{ Método de tutoramento } \\
\hline Cruzado & $1,2 \mathrm{~b}$ & $1,1^{\text {ns }}$ & $3,3^{\text {ns }}$ & $2,2 \mathrm{a}$ & $1,1^{\mathrm{ns}}$ & $1,1^{\mathrm{ns}}$ \\
\hline 'Mexicano' & $1,8 a b$ & 1,0 & 3,6 & $1,5 \mathrm{~b}$ & 0,7 & 0,8 \\
\hline Vertical com bambu & $1,5 a b$ & 1,1 & 4,1 & $1,7 \mathrm{~b}$ & 0,8 & 0,9 \\
\hline Vertical com fitilho & $2,1 \mathrm{a}$ & 1,1 & 4,4 & $1,8 \mathrm{~b}$ & 0,7 & 1,1 \\
\hline \multicolumn{7}{|c|}{$\begin{array}{l}\text { Método de condução } \\
\text { (número de hastes por planta) }\end{array}$} \\
\hline Uma haste & $1,7^{\mathrm{ns}}$ & $1,1^{\text {ns }}$ & $4,7 \mathrm{a}$ & $1,8^{\text {ns }}$ & $0,9^{\text {ns }}$ & $0,9^{\text {ns }}$ \\
\hline Duas hastes & 1,6 & 1,1 & $3,0 \mathrm{~b}$ & 1,8 & 0,8 & 1,0 \\
\hline Média & 1,7 & 1,1 & 3,8 & 1,8 & 0,8 & 0,9 \\
\hline CV (\%) & 29,4 & 41,5 & 31,4 & 38,7 & 39,4 & 30,5 \\
\hline
\end{tabular}

${ }^{1}$ Médias seguidas pela mesma letra na coluna, dentro de cada fator analisado, não diferem entre si pelo teste de Tukey $(\alpha=0,05)$

cha bacteriana na safra 2004/2005. No método 'mexicano', além de as plantas se apoiarem sobre os fitilhos dispostos horizontalmente nos dois lados ao longo da fila de plantas, elas também se apóiam umas nas outras. Desta forma, há maior proximidade entre plantas, favorecendo a disseminação da mancha bacteriana, pelos respingos de chuva. Entretanto, os resultados mostram que, principalmente para as doenças fúngicas analisadas, todos os métodos de tutoramento vertical promovem condições semelhantes e desfavoráveis ao seu desenvolvimento.

Para os métodos de condução de plantas, observaram-se diferenças significativas somente para severidade de mancha bacteriana, na safra 2005/2006, na cultivar San Vito, sendo que a con- 
dução de uma haste por planta proporcionou maior severidade da doença, em relação à condução de duas hastes por planta. Esta resposta pode estar ligada ao menor espaçamento entre plantas com a condução de uma haste por planta, facilitando a disseminação da doença. Além disso, o adensamento de plantas proporciona maior cobertura dos órgãos pelas folhas, podendo dificultar a penetração da calda fungicida e reduzir a sua cobertura.

Danos em frutos - As cultivares Carmen, na safra 2004/2005, e San Vito, na safra 2005/2006, apresentaram maior porcentagem de frutos com doenças fitopatológicas ou fisiológicas em relação às cultivares Débora Max e Nemo Netta, respectivamente (Tabela 3). Estes resultados ratificam a avaliação de cultivares para o Estado de Santa Catarina 2006/2007 (Epagri, 2006), onde as cultivares Carmen e San Vito apresentam menor porcentagem de frutos comerciais em relação a Débora Max e Nemo Netta, respectivamente.

Houve diferenças entre métodos de tutoramento para porcentagens de frutos doentes somente na safra 2004/2005 (Tabela 3). Nesta safra, o método de tutoramento vertical com fitilho e o método de tutoramento cruzado apresentaram maior e menor porcentagem de frutos doentes, respectivamente, ambos não diferindo dos demais métodos de tutoramento. Em trabalhos anteriores não foram observadas diferenças entre métodos de condução vertical e cruzado para porcentagem de frutos com danos por Alternaria solani (Silva et al., 1997; Santos et al., 1999), Erwinia spp., Phoma destructiva (Santos et al., 1999) e para frutos com diversos tipos de defeitos (Silva et al., 1997; Marim et al., 2005). Entretanto, Silva et al. (1997) encontraram maior produção de frutos com podridão apical no método de tutoramento vertical em relação ao cruzado.

A porcentagem de frutos doentes foi maior na condução de uma haste por planta na safra 2005/2006, em relação à condução de duas hastes por planta (Tabela 3). Na safra 2004/2005, não houve diferença entre métodos de condução para porcentagem de frutos doentes. Oliveira et al. (1996) encontraram maior número de frutos rachados e amarelecidos com a condução de uma haste por planta, em relação à condução de duas hastes por planta, atribuindo estes danos à menor proteção dos frutos pelas folhas contra a radiação solar direta. Entretanto, estes autores não observaram diferenças para podridão apical e lóculo aberto enquanto que Marim et al. (2005) não encontraram diferenças para produção de frutos com defeitos para condução com uma ou duas hastes por planta.

Já para frutos com danos de brocas, somente na safra 2005/2006 houve diferenças entre cultivares, sendo que a cultivar San Vito apresentou maior porcentagem de frutos atacados, tanto por broca grande como por broca-pequenado-tomateiro (Tabela 3).

Considerando os métodos de tutoramento, houve diferenças somente na safra 2005/2006, sendo que o método cruzado apresentou maior porcentagem de frutos atacados por brocas em relação aos métodos verticais (Tabela 3 ). A diferença entre os métodos de tutoramento vertical e cruzado para porcentagem de frutos atacados por brocas se deve ao somatório do ataque por broca-grande e broca-pequena-do-tomateiro, visto que analisando isoladamente o ataque de cada espécie de inseto-praga não houve diferenças entre os métodos de tutoramento. Picanço et al. (1995) observaram menor ataque de traça-dotomateiro às folhas e aos frutos quando as plantas estavam totalmente desenvolvidas no tutoramento vertical, em relação ao cruzado, apesar do menor espaçamento utilizado no vertical. Estes autores atribuíram o menor ataque à maior exposição das folhas do tomateiro à calda inseticida, no tutoramento vertical, já que as plantas foram pulverizadas nos dois lados. Entre métodos de tutoramento vertical, não houve diferenças para porcentagem de frutos com brocas. Da mesma forma, os métodos de condução não influenciaram a porcentagem de frutos atacados por brocas nas duas safras analisadas (Tabela 3).

De acordo com os resultados, os métodos de tutoramento vertical proporcionam menor severidade de doença e ataque de insetos-praga, em relação ao método de tutoramento cruzado. Por sua vez, a condução de uma haste por plan- ta não apresenta diferenças na severidade de doenças foliares e porcentagem de frutos com ataque de insetos-praga, em relação à condução de duas hastes por planta. Assim, os métodos de tutoramento vertical de plantas, com uma ou duas hastes por planta, são recomendados dentro de sistemas de produção que objetivam o controle mais racional de insetos-praga e doenças.

\section{AGRADECIMENTOS}

Os autores agradecem as empresas Agrocinco/Nirit Seeds Ltda e Sakata Seed Sudamérica Ltda pelo apoio na implantação dos experimentos.

\section{REFERÊNCIAS}

AGROCINCO. 2006. Produtos. Disponível em: < ht t p ://ww w.agrocinco.com.br/ index_portugues.htm>. Acesso em: 2 jun. 2006.

BECKER WF. 2005. Validação de dois sistemas de previsão para o controle da requeima do tomateiro na região de Caçador, SC. Agropecuária Catarinense 18: 63-68.

BOFF P; FONTES PCR; VALE FX; ZAMBOLIM L. 1992. Controle da mancha de estenfílio e da pinta-preta do tomateiro em função do sistema de condução. Horticultura brasileira 10: 25-27.

BOFF P; RIBEIRO DO VALE FX; ZAMBOLIM L; FONTES PCR. 1991. Epidemiologia comparativa da mancha-de-estenfílio (Stemphylium solani) e da pinta-preta (Alternaria solani), em dois sistemas de condução do tomateiro. Fitopatologia brasileira 16: 104-109.

BOFF P; ZAMBOLIM L; RIBEIRO DO VALE FX. 1991. Escalas para avaliação de severidade da mancha-de-estenfílio (Stemphylium solani) e da pinta-preta (Alternaria solani) em tomateiro. Fitopatologia Brasileira 16: 280-283.

EPAGRI. 1997. Normas técnicas para o tomateiro tutorado na região do Alto Vale do Rio do Peixe. Florianópolis: EPAGRI. 60p. (EPAGRI. Sistemas de Produção, 27).

EPAGRI. 2006. Avaliação de cultivares para o Estado de Santa Catarina 2006/2007. Florianópolis: EPAGRI. 162p. (EPAGRI. Boletim Técnico, 128).

JAMES WC. 1971. An illustrated series of assessment keys for plant diseases. their preparations and usages. Canadian Plant Disease Survey 51: 39-65.

KREUZ CL. 2003. Análise da competitividade de atividades agrícolas na região de Caçador, Santa Catarina. Florianópolis: EPAGRI. 52p. (EPAGRI. Documentos, 209).

KUROZAWA C; PAVAN MA. 2005. Doenças do Tomateiro. In: KIMATI H; AMORIM L; BERGAMIN FILHO A; CAMARGO LEA; REZ6ENDE JAM (eds.) Manual de fitopatologia: doenças das plantas cultivadas. São Paulo: Agronômica Ceres. p. 607-626. 
MARIM BG; SILVA DJH; GUIMARÃES MA; BELFORT G. 2005. Sistemas de tutoramento e condução do tomateiro visando produção de frutos para consumo in natura. Horticultura Brasileira 23: 951-955.

MELLO SC; TAKATSU A; LOPES CA. 1997. Escala diagramática para avaliação da manchabacteriana do tomateiro. Fitopatologia Brasileira 22: 447-448.

MELO PCT; VILELA NJ. 2005. Desafios e perspectivas para a cadeia brasileira do tomate para processamento industrial. Horticultura Brasileira 23: 154-157.

OLIVEIRA VR; FONTES PCR; CAMPOS JP; REIS FP. 1996. Qualidade do tomateiro afetada pelo número de ramos por planta e pela poda apical. Revista Ceres 43: 309-318.
PANDOLFO C; BRAGA HJ; SILVAJÚNIOR VP. MASSIGNAM AM; PEREIRA ES; THOMÉ UMR. 2002. Atlas climatológico do Estado de Santa Catarina. Florianópolis: EPAGRI. [CDROM].

PICANÇO M; GUEDES RNC; LEITE GLD; FONTES PCR; SILVA EA. 1995. Incidência de Scrobipalpuloides absoluta em tomateiro sob diferentes sistemas de tutoramento e de controle químico. Horticultura brasileira 13: 180-183.

REBELO JA. 1993. Sistema alternativo de tutoramento para tomateiro. Horticultura Brasileira 11: 161.

SAKATA SEED SUDAMERICA. 2006. Catálogo de produtos. Disponível em: <http:// www.sakata.com.br/index $\cdot$ php? action $=$ catalogo\&local $=$ br $\&$ cultura $=4 \&$ language $=p t>$. Acesso em: 2 jun. 2006.
SANTOS HS; PERIN WH; TITATO LG; VIDA JB; CALLEGARI O. 1999. Avaliação de sistemas de condução em relação à severidade de doenças e à produção do tomateiro. Acta Scientiarum 21: 453-457.

SILVA DJH; SEDIYAMA MAN; MATA AC; PICANÇO MC. 1997. Produção de frutos de tomateiro (Lycopersicon esculentum Mill) em quatro sistemas de cultivo. Revista Ceres 44: 129-141.

TAGLIARI PS. 2003. Tomate em plantio direto: menos agrotóxicos, mais renda e mais saúde. Agropecuária Catarinense 16: 24-29.

WAMSER AF; MUELLER S; BECKER WF; SANTOS JP. 2007. Produção do tomateiro em função dos sistemas de condução de plantas. Horticultura Brasileira 25: 238-243. 